\title{
A Comparative Analysis of Corporate and Independent Foundations
}

\author{
Justin Koushyar, Wesley Longhofer, Peter W. Roberts
}

Emory University

Abstract: Notwithstanding some visible debates, systematic evidence about the implications of greater corporate involvement in the social sector is sparse. We provide some of this evidence by examining one channel of corporate influence within the nonprofit sector-company sponsorship of philanthropic foundations. Our analysis shows that corporate foundations raise more funds and distribute grants with lower overhead than similar independent (i.e., non-corporate) foundations. However, their grantmaking is also more dispersed and less relational, and they tend to be governed by more ephemeral groups of officers and trustees. These findings suggest that corporate foundations benefit from having access to the resources of the companies that sponsor them but are constrained by their additional market-based motivations. The findings also update and refine what nonprofits might expect from corporate foundations relative to their more traditional independent counterparts.

Keywords: foundations; corporate philanthropy; organizations

Citation: Koushyar, Justin, Wesley Longhofer and Peter W. Roberts. 2015. "A Comparative Analysis of Corporate and Independent Foundations." Sociological Science 2: 582-596.

Received: December 15, 2014

Accepted: February 19, 2015

Published: December 15, 2015

Editor(s): Jesper Sørensen, Sarah Soule

DOI: $10.15195 / \mathrm{v} 2 . \mathrm{a} 28$

Copyright: (C) 2015 The Author(s). This open-access article has been published under a Creative Commons Attribution License, which allows unrestricted use, distribution and reproduction, in any form, as long as the original author and source have been credited. (C) (i)
$\mathrm{R}^{\mathrm{k}}$ ESEARCH on corporate philanthropy tends to focus on how giving can augment a firm's competitive or financial performance (Margolis and Walsh 2003). Indeed, a sizeable literature speaks to when and how corporate giving provides benefits by boosting a firm's reputation (Fombrun and Shanley 1990), enhancing customer loyalty (Burt 1983), or improving employee recruitment, satisfaction, and retention (Greening and Turban 2000). More recently, some business researchers are suggesting that these company benefits are also good for society because they provide incentives to funnel additional resources into the nonprofit sector (Porter and Kramer 2006). However, empirical research on the actual societal implications of corporate giving is relatively sparse (Guthrie 2010). This scant attention is surprising because the stated potential for positive societal impacts comes with concerns about greater corporate involvement in the public sphere. Detractors argue that the additional market-based motivations that come with corporate participation create problems when it comes to societal reliance on for-profit companies.

For these opposing reasons, corporate foundations-also called companysponsored foundations-are potentially important funders of public goods and services despite the uneasy tension that exists between the needs of social sector organizations and companies' private financial interests. Optimism is bolstered by the fact that these corporate foundations have access to the financial resources and business acumen deployed by their sponsor companies, thus making them better suited to strategize, support, and commit to social programs that deliver scalable benefits. Pessimism is muted by the fact that corporate foundations are both organizationally and legally distinct from their parent firms and may be shielded from the 
firms' financial interests or managerial preferences (Walker 2013; Brown, Helland, and Smith 2006).

Notwithstanding this uneasy promise, little empirical attention has been paid to the fundraising and giving patterns of corporate foundations compared to their non-corporate (i.e., independent) counterparts. This kind of focused comparative analysis would shed light on whether corporate foundations are indeed able to leverage private-sector sponsors and make more resources available to nonprofits. It would also show whether they are sufficiently distanced from their sponsor companies to, in effect, mirror their non-corporate counterparts when it comes to distributing these funds to grantees. Or do corporate foundations, acting as pseudo-agents of their parent companies, enact the managerial preferences and stakeholder expectations of their sponsors?

In this article, we compare a matched sample of corporate and independent foundations to shed light on these questions. We begin by examining whether corporate foundations are able to translate the resources and business acumen of their sponsors into more effective fundraising and more cost-effective foundation administration. We then assess whether the additional interests of numerous company stakeholders make it more challenging for corporate foundations to focus on specific sets of philanthropic organizations and relationships. Consistent with resource dependence theory (Pfeffer and Salancik 1978), we propose that linking foundation giving to brand development and stakeholder management impedes a corporate foundation's ability to focus on a smaller, more targeted set of grantees. Moreover, the desire to appease company stakeholders in ways that are not overly burdensome can lead corporate foundations to have trustees and advisors that are less committed to the social goals of the foundation.

The balance of this article is structured as follows. The next section briefly discusses the emergence of corporate foundations in the United States. We then develop a set of expectations about specific behavioral differences between corporate and independent foundations, including those related to fundraising and giving patterns. We then test these expectations using a matched sample of corporate and independent foundations operating in the United States in 2005 and 2009. We conclude the article by discussing the implications of our findings for growing debates about the implications of greater corporate involvement in the social sector.

\section{Comparing Independent and Corporate Foundations}

U.S. industrialist Andrew Carnegie famously argued that the duty of the wealthy is "to provide moderately for the legitimate wants of those dependent on him; and after doing so to consider all surplus revenues which come to him as trust funds, which he is called upon to administer ... in the manner which, in his judgment, is best calculated to produce the most beneficial results for the community" (Carnegie 1889). In this spirit, Carnegie used his wealth and influence to stimulate the construction of over 2,800 public libraries across the United States (Dowie 2001). As Carnegie was setting a stage for industrialist philanthropy, John D. Rockefeller was using his position to improve society by finding and then eliminating "the root causes of many societal ills." As Rockefeller's personal fortune grew, it became increasingly 
difficult to manage these diverse socially oriented activities. Seeking someone with experience to manage his philanthropic endeavors, he hired the Reverend Fredrick Gates, who is credited as being one of the first and prototypical professionals in the philanthropic sector. This practice of allowing large amounts of financial wealth to be professionally managed to target and pursue specific social objectives was the forerunner of the modern philanthropic foundation (Prewitt 2006).

It was not until a 1952 court ruling gave managers the ability to engage in corporate philanthropy without the fear of legal repercussions that corporate-sponsored foundations began to emerge. In 1951, the A. P. Smith Manufacturing Company made a $\$ 1,500$ donation to Princeton University that was subsequently challenged in court by a group of investors. In a pivotal ruling the following year, the court found in favor of the management of A. P. Smith, paving the way for rapid growth in the number of corporate foundations. Thus, according to Nelson (1970) the vast majority of the largest corporate foundations that were active in the mid-1960s were established after 1950. Although many of these disappeared in the merger and acquisition waves of the 1980s, the rise of new company wealth in the 1990s has led to a resurgence of corporate foundations in the United States (Galaskiewicz, Bielefeld, and Dowell 2006). Today, it is estimated that 40 percent of all U.S. companies have their own philanthropic foundations (Guthrie 2010).

In terms of their stated and fiduciary objectives, corporate foundations are no different than their independent counterparts (Galaskiewicz and Sinclair-Colman 2006). Both are nonprofit grantmaking organizations set up to gather funds from various sources and then distribute those funds to other nonprofits pursuing specific societal objectives. However, there are reasons to suspect corporate foundations might differ in terms of their fundraising, grantmaking, and governance. The most salient factor that distinguishes corporate from independent foundations is their formal association with active, for-profit companies. Thus we might expect the greater financial surpluses, enhanced marketing and administrative capabilities, and cross-subsidization with excess human and technical resources to allow corporate foundations to be both more effective at raising funds and more efficient at administering them with lower overhead expenses.

We might also expect corporate foundations to align their social objectives with the broader commercial goals of their sponsors. Philanthropy may benefit companies specifically by increasing sales and company goodwill. Thus, as corporate foundations attend to the varied interests of their parent companies' stakeholders, it is likely they will give out more but smaller grants than their independent counterparts. Moreover, because the perceptual value of claims of social support lasts beyond the duration of any specific grant, corporate foundations should tend to shift their support dynamically and be less relational in their grantmaking. A final way that commercial motivations might influence outcomes is through foundation governance. Because corporate foundation appointments are, in part, rooted in the impression-management interests of the sponsor company, appointments might also be more symbolic. With this lowered level of intrinsic commitment to the mission of the foundation, corporate foundations should exhibit a lower level of officer and trustee continuity than independent foundations. 


\section{Data and Analysis}

We explore these possibilities in an analysis of a matched random sample of philanthropic foundations that operated across the United States in 2005 and 2009. The 2010 edition of The Foundation Directory Online reports on the top 97,000 U.S. foundations by total giving of which 2,896 are corporate foundations. From this source, we selected a random sample of ten percent of all corporate foundations, proportionately weighted by state concentration. To obtain a corresponding sample of independent foundations, we matched each corporate foundation to an independent foundation that was established in the same year and in the same state. This matching procedure accounts for differences in the temporal and spatial conditions that imprint foundations when they are established (Stinchcombe 1965). We then extracted financial information for the 2005 and 2009 tax years from the informational forms ${ }^{1}$ (i.e., 990s) filed by each sampled foundation. These forms were obtained from the National Center for Charitable Statistics (NCCS) or from Guidestar (www . guidestar .org).

The foundations in this sample differ in several ways that relate to the flow of support into the nonprofit sector. First, there is variance in the size of the endowments that foundations develop and draw from. Foundations like the Ann Ratner Charitable Foundation (an independent foundation established in 2003) hold few assets—in this case, roughly $\$ 9,300$ in 2005-and rely primarily on year-to-year contributions from supporters. At the other end of the continuum, the Monsanto Fund (a corporate foundation established in 1962) deploys the investment proceeds from a roughly $\$ 9$ million endowment. In addition to their endowment incomes, foundations vary in their ability to raise funds from other sources. The John P. Murphy Foundation raised zero funds from outside sources in 2009, while the Bank Atlantic Foundation raised more than \$700,000 in 2005 alone Similar differences are observed in the overhead expenses that foundations incur. These expenses are material because every dollar that a foundation spends on administration does not make its way to a nonprofit grantee. The Dorothy D. Graham Scholarship Fund spent roughly 32.5 percent of its total expenses on overhead in 2009. At the other extreme the CORE Construction Foundation spent less than one percent of its total expenses on overhead in that same year.

There are also differences in the patterns of grantmaking across foundations. For example, the Taco John's Foundation gave grants that averaged just \$907 in 2009, compared to grants from the Dan E. and Neva L. Brannin Foundation that averaged more than $\$ 39,000$. Along with differences in average grant size are differences in the tendency to support the same nonprofits over time. Of all the nonprofits funded by the Merklin Family Foundation in 2005, none were supported again in 2009. By contrast, 80 percent of the nonprofits funded by the Lipton Foundation in 2005 were also funded four years later. Finally, foundations differ in the causes that they support. More than 70 percent of the grants from Mitsubishi Electric American Foundation in 2009 went to what would be called social welfare organizations. The Ginn Family Foundation in 2009, by comparison, made over 91 percent of its grants to eliteoriented nonprofits that focus on the arts and on sports and recreation. 
Table 1: Variable Definitions

\begin{tabular}{ll}
\hline Variable Name & Definition \\
\hline Funds Raised & Dollars raised, logged \\
Administration Ratio & Administrative expenses/(administrative expenses + total grant expenses) \\
Average Grant Size & Total grant expenses/total number of grantees \\
Grantee Continuity & Sampled grantees with grants in both years/grantees with grants in 2005 \\
Percent Elite-oriented & Dollar value of grants to elite-oriented nonprofits/total grant expenses \\
Percent Social welfare & Dollar value of grants to social welfare nonprofits/total grant expenses \\
Officer \& Trustee & Number of 2005 officers and trustees that remain in place 2009/ \\
\multicolumn{1}{c}{ Continuity } & total 2005 officers and trustees \\
\hline
\end{tabular}

We created several variables that build on these observations; see Table 1 for variable definitions. The funds raised variable measures the total dollars raised by a foundation in each year. This variable is log-transformed to account for its pronounced skew. The administration ratio variable equals a foundation's total administrative expenses in a year divided by the sum of its administrative and total grant expenses. It therefore measures the percentage of funds that are used for overhead functions rather than for the direct support of nonprofits.

An examination of grantmaking patterns requires additional information on specific grants and grantees. We extracted these data manually from the sampled foundations' informational returns. Every year, foundations provide comprehensive rosters of their grantees in Section XV of their 990 forms. These provide the names of all grantees and the size of the corresponding grants. The count of grants is the total number of grants made by a foundation in a given year. The average grant size equals a foundation's total grant expenses in a year divided by the total number of grantees. Again, the latter variable is log-transformed.

The grantee continuity variable measures the durability of the funding relationships between a foundation and its grantees. Beginning with the sample of grantees in 2005, we manually searched through the entire roster of foundation grantees in the 2009 observation year. A match was recorded when we found a grantee with the same name and geographic location in that subsequent year. The continuity measure is the number of sampled grantees that receive grants across the two observation years divided by the number of sampled grantees in 2005. This variable ranges from zero (when no sampled grantees received repeated support from the foundation) to one (when the foundation committed to repeated support for all of the sampled 2005 grantees).

The variables that describe the sector focus of each foundation require additional information about the philanthropic sectors of grantees. Unfortunately, there is no uniform reporting this information for the more than 61,000 grants made by the sampled foundations in the two years covered in our analysis. Therefore, for each foundation in each year, we manually searched for this information from either thirteen grantees or from a randomly selected thirteen percent of all reported grantees, whichever number was larger. ${ }^{2}$ A very small number of grantees with indiscernible names, grantees with international locations, or bulk grants (i.e., multi- 
ple grants made to multiple entities with no way to distinguish individual grantees) were set aside. For the remainder, reported grantee names were entered into online repositories of public charity information-Guidestar, NCCS, and Google-to locate Employee Identification Numbers (EINs). Using these EINs, we searched the NCCS Core Files to determine the philanthropic sector classification for each grantee. ${ }^{3}$ In the end, we were able to clearly identify the sector for roughly 80 percent of the sampled grantees (roughly 11,000 in total). ${ }^{4}$

The NCCS uses the National Taxonomy of Exempt Entities (NTEE) to classify nonprofits into 26 groups ranging from arts/culture/humanities to mutual/ membership benefit organizations ${ }^{5}$ We used this classification to determine whether a grantee is considered elite-oriented or social welfare. Here, we follow Marquis, Davis, and Glynn (2013) and classify arts/culture/humanities, philanthropy, and recreation/sport nonprofits (NTEE Categories A, T, and N) as elite-oriented. Social services grantees focus on mental health, employment, housing, healthcare, public safety, youth development, human services, civil rights, public benefit and food/nutrition (NTEE Categories E, F, J, K L, M, O, P, R, and W). After assigning each grantee to its orientation group, we calculated percentages. The percent eliteoriented variable is the percentage of funds that a foundation grants to elite-oriented nonprofits, and the percent social welfare variable is the corresponding percentage given to social welfare nonprofits.

Foundation governance information for each foundation was obtained from Section VII of the 990s. This section contains a list of officers, directors, managers, and trustees for each foundation. ${ }^{6}$ Beginning with all 2005 names, we manually searched through the list of officers and trustees in the 2009 informational form. The officer and trustee continuity variable is the percentage of individuals from 2005 who are still present in 2009.

We began with a sample of 290 corporate foundations and 290 independent foundations observed in two different years. Missing grant-level data reduced the final sample to 942 observations from 471 foundations. However, the final sample size is just 471 for the grantee and officer/trustee continuity analyses because these analyses are based on a single time interval: 2005 to 2009. Table 2 provides descriptive statistics and pair-wise correlations for all variables of interest.

Our empirical strategy is to look for systematic differences across the specified variables that are attributable to a foundation being controlled by a for-profit company. Because we effectively over-sample corporate foundations, we estimated probability-weighted regression models, with the weights being the share of sampled corporate and independent foundations in each state in each year. These counts were obtained from the Foundation Center website. ${ }^{7}$ Then, to account for the non-independence of the same-foundation observations, we cluster the models' error terms on foundations.

All models control for foundation age (to reflect imperfections in our matching process) and include a fixed year effect for 2009. State fixed effects are also included to account for unobserved heterogeneity across states. Models 1 and 2 contain additional controls for the asset size (logged) for each foundation. In the funds raised model, foundations with larger asset bases may rely more heavily on earned income and feel less pressure to raise additional funds. In the administration ratio 


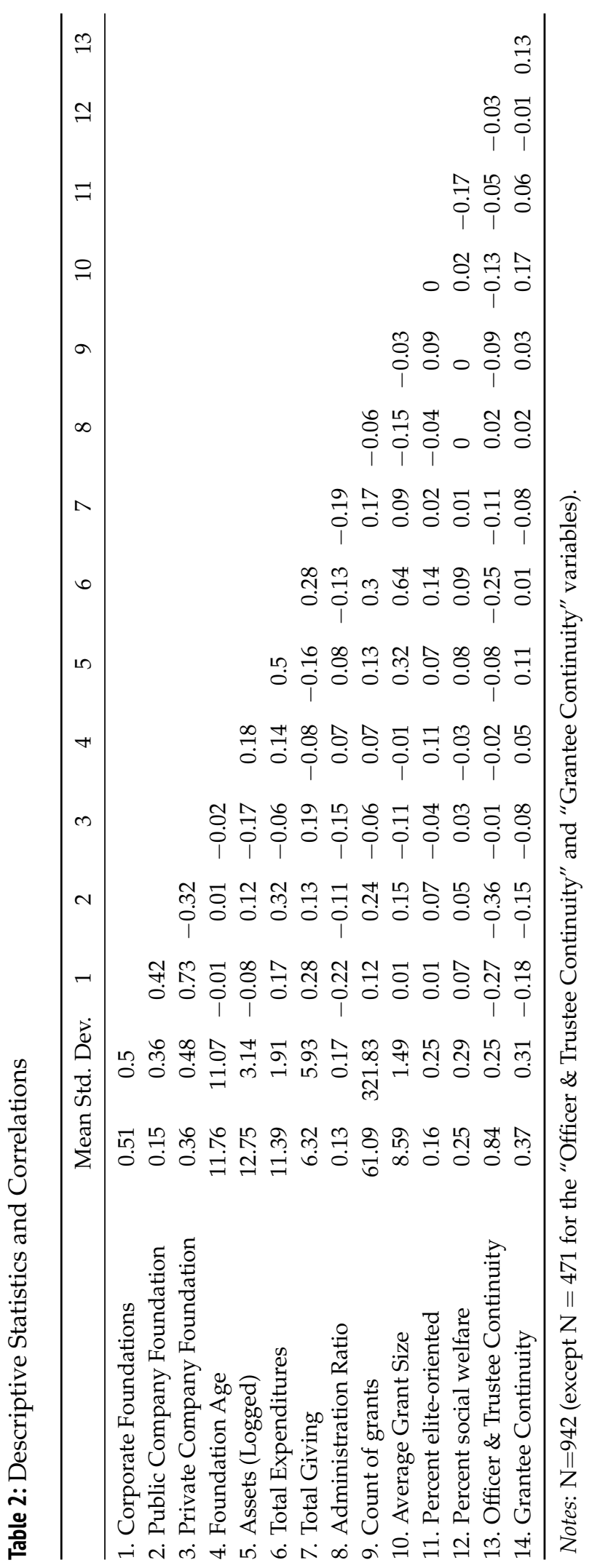


model, foundations that have large endowments to manage may incur additional overhead expenses relative to those that rely on current donations alone. We also control for the total expenditures of each foundation (logged) in models $2-8$. Due to possible economies of scale, larger foundations may have lower administration ratios. Larger foundations may also tend to give more or larger grants simply because they have more funds to distribute. Finally, larger foundations may also spread their larger sums of money across more sectors.

\section{Results}

The coefficient estimates reported in Tables 3 and 4 indicate little in the way of systematic variation in regard to foundation age. Systematic differences emerge, however, when we examine the coefficients associated with the corporate foundation variable. Model 1 reports a positive and significant effect on total funds raised. The estimated effect suggests that, all else equal, corporate foundations raise roughly three times more per year than their independent counterparts. This effect is not due to the fact that the endowments of corporate foundations tend be smaller. While the average of the log-of-assets control variable is slightly smaller for the corporate foundations-12.51 compared to 13.00 for independent foundations-its estimated coefficient is not significantly different from zero.

Model 2 focuses on administration ratios. It seems sensible that foundations that spend more money in a given year (i.e., the corporate foundations on average) might benefit from economies of scale. As expected, the effect of the log of total foundation expenditures variable on the administration ratio is negative and significant. We also find that foundations with more assets under management incur additional expenditures that make their administration ratios significantly larger. Notwithstanding these two effects, the negative coefficient on the corporate foundation variable suggests that, all else equal, they operate with lower paid overheads. $^{8}$

These two significant corporate foundation effects corroborate expectations that the additional resources and/or business acumen of corporate sponsors tend to make more funds available to grantee organizations, in terms of both overall fundraising and more cost-effective administration. However, given their added motivation of connecting with numerous customers and employees and otherwise addressing the interests and social proclivities of a wide range of company stakeholders, grantmaking in corporate foundations is also expected to be less focused. Indeed, the positive and significant coefficient on the corporate foundation variable in model 3 (Table 4) suggests that corporate foundations do spread their funds across a larger number of grantees. This effect is evident even after controlling for the fact that corporate foundations also tend to have more funds to distribute. We also find, as expected, that total foundation expenditures have a positive and significant effect on average grant size (see model 4). That said, the negative and significant coefficient estimate in model 4 suggests that grants from corporate foundations tend to be smaller on average. More specifically, the estimated effect implies that grants from corporate foundations are, on average, 44 percent smaller than grants from independent foundations. Thus, although corporate foundations are 
Table 3: Regression Results: Fundraising and Administration Expenses

(1)

\begin{tabular}{lcc} 
& $(1)$ & $(2)$ \\
& Funds Raised & Admin. Ratio \\
\hline Corporate Foundation & $3.142^{*}$ & $-0.050^{*}$ \\
& $(0.493)$ & $(0.014)$ \\
Foundation Age & -0.022 & -0.000 \\
& $(0.039)$ & $(0.001)$ \\
Assets $(\log )$ & -0.155 & $0.013^{*}$ \\
& $(0.107)$ & $(0.004)$ \\
Total expenditures $(\log )$ & & $0.019^{*}$ \\
& & $(0.007)$ \\
Constant & $8.094^{*}$ & $0.157^{\dagger}$ \\
Adj. $R^{2}$ & $(3.917)$ & $(0.084)$ \\
\hline
\end{tabular}

Notes: All parameter estimates are obtained from probability weighted ordinary least squares regression models. Models include fixed effects for year $=2009$ and for the fifty US states. N=942.

$* p<0.05 ;+p<0.10$.

able to raise and disperse more funds in a given year, they also tend to distribute them more widely and in smaller amounts.

Model 5 shows that corporate foundations are also significantly less likely than independents to continue funding any one grantee across the two years in the sample. ${ }^{9}$ On average, approximately 42 percent of the sampled recipients of grants from independent foundations in 2005 received additional grant support four years later, compared to roughly 31 percent for the corporate foundation grantees.

The next models in Table 4 consider how grantmaking is distributed across nonprofit sectors. The results in models 6 and 7 suggest there are no meaningful differences in the propensity to grant to elite-oriented or social welfare nonprofits. The simple averages corroborate these insignificant coefficients. On average, the corporate foundations in the sample give 15.9 percent of their grant dollars to eliteoriented nonprofits and 26.7 percent to social welfare organizations. These figures compare with 15.3 percent and 228 percent for the independent foundations.

The final model in Table 4 examines the likelihood that any one officer or trustee from 2005 will also be on the board in 2009. Here, we also observe a lower probability that a 2005 corporate foundation officer or trustee is retained in 2009 , as predicted. The magnitude of this effect suggests that a corporate foundation officer is roughly 13 percent less likely than an officer of an independent foundation to remain in her position four years later. ${ }^{10}$

\section{Public versus Private Company Sponsors}

In a final analysis, we examine separately the implications of foundations having public versus privately held company sponsors. The crux of a resource-dependence argument is that the additional motivations of company sponsors influence foun- 
Table 4: Regression Results: Grant Making and Foundation Governance

\begin{tabular}{lcccccc}
\hline & $\begin{array}{c}(3) \\
\text { Count of } \\
\text { Grants }\end{array}$ & $\begin{array}{c}(4) \\
\text { Average } \\
\text { Grant Size }\end{array}$ & $\begin{array}{c}(5) \\
\text { Grantee } \\
\text { Continuity }\end{array}$ & $\begin{array}{c}(6) \\
\text { Percent } \\
\text { Elite }\end{array}$ & $\begin{array}{c}(7) \\
\text { Percent } \\
\text { Soc. Welf. }\end{array}$ & $\begin{array}{c}(8) \\
\text { Conustee } \\
\text { Continuity }\end{array}$ \\
\hline Corporate Foundation & $0.854^{*}$ & $-0.445^{*}$ & $-0.114^{*}$ & -0.004 & 0.03 & $-0.132^{*}$ \\
& $(0.165)$ & $(0.129)$ & $(0.031)$ & $(0.021)$ & $(0.026)$ & $(0.027)$ \\
Foundation Age & $0.024^{*}$ & $-0.020^{*}$ & -0.001 & 0.002 & 0.001 & 0.000 \\
Total expenditures (log) & $(0.008)$ & $(0.009)$ & $(0.002)$ & $(0.001)$ & $(0.002)$ & $(0.001)$ \\
Constant & $0.388^{*}$ & $0.696^{*}$ & 0.014 & 0.008 & 0.016 & -0.008 \\
& $(0.05)$ & $(0.08)$ & $(0.013)$ & $(0.009)$ & $(0.01)$ & $(0.008)$ \\
Observations & $-2.231^{*}$ & $1.555^{+}$ & -0.036 & 0.017 & $-0.153^{\dagger}$ & $0.914^{*}$ \\
Adj. $R^{2}$ & $(0.612)$ & $(0.93)$ & $(0.133)$ & $(0.117)$ & $(0.09)$ & $(0.139)$ \\
\hline
\end{tabular}

Notes: All parameter estimates are obtained from probability weighted ordinary least squares regression models. Models include fixed effects for year $=2009$ and for the fifty US states. The Count of Grants parameter estimates are obtained from a negative binomial regression model. The remaining estimates are obtained from probability weighted ordinary least squares regression models. Models include fixed effects for year $=2009$ and for the fifty US states.

$* p<0.05 ;+p<0.10$.

dation behaviors because, at the margin, they manage their foundations to further company interests. In the extreme case of private and tightly held companies, it is not clear why the incentives of company owners would diverge from those of individual philanthropists; they are, in effect, the same individuals. However, as a company becomes more widely owned, investor interests become more dispersed and impersonal, and the emphasis on financial performance intensifies. We expect that this latter scenario-with its more explicit emphasis on encouraging behaviors that enhance commercial performance-will produce more stark differences between independent and corporate foundations.

The models in Table 5 decompose the corporate foundation variable into separate indicators of public-company versus private-company sponsorship. In support of this thinking about the implications of sponsor type, the absolute values of public-company foundation effects are greater than the corresponding private-company foundation effects in all of the models that yield significant results in Table 4. Honing in on the models where these public-private differences are significant or nearly significant yields the following observations. Public-company foundations issue significantly more grants $\left(\chi^{2}=7.22 ; p=0.01\right)$ than their private-company counterparts. They are also significantly less likely to continue funding the same grantees $\left(\chi^{2}=2.52 ; p=0.11\right)$ four years later. Relative to independent foundations, 2005 grantees are 18 percent less likely to receive support again in 2009 from a foundation sponsored by a public corporation, but only nine percent less likely to receive continued support from a private company's foundation. Finally, the relative turnover 
Table 5: Public versus Private Company Sponsors

\begin{tabular}{lcccccc}
\hline & $(3)$ & $(4)$ & $(5)$ & $(6)$ & $(7)$ & $(8)$ \\
& $\begin{array}{c}\text { Count of } \\
\text { Grants }\end{array}$ & $\begin{array}{c}\text { Average } \\
\text { Grant Size }\end{array}$ & $\begin{array}{c}\text { Grantee } \\
\text { Continuity }\end{array}$ & $\begin{array}{c}\text { Percent } \\
\text { Elite }\end{array}$ & $\begin{array}{c}\text { Percent } \\
\text { Soc. Welf. }\end{array}$ & $\begin{array}{c}\text { Trustee } \\
\text { Continuity }\end{array}$ \\
\hline Public Company Foundation & $1.365^{*}$ & $-0.642^{*}$ & $-0.176^{*}$ & 0.039 & 0.013 & $-0.254^{*}$ \\
& $(0.312)$ & $(0.261)$ & $(0.051)$ & $(0.036)$ & $(0.041)$ & $(0.044)$ \\
Private Company Foundation & $0.536^{*}$ & $-0.359^{*}$ & $-0.087^{*}$ & -0.023 & 0.038 & $-0.079^{*}$ \\
& $(0.11)$ & $(0.115)$ & $(0.035)$ & $(0.023)$ & $(0.029)$ & $(0.029)$ \\
Foundation Age & $0.024^{*}$ & $-0.020^{*}$ & -0.001 & 0.002 & 0.001 & 0.000 \\
Total expenditures $(\log )$ & $(0.007)$ & $(0.009)$ & $(0.002)$ & $(0.001)$ & $(0.002)$ & $(0.001)$ \\
& $0.380^{*}$ & $0.697^{*}$ & 0.014 & 0.008 & 0.016 & -0.007 \\
Constant & $(0.05)$ & $(0.081)$ & $(0.014)$ & $(0.009)$ & $(0.01)$ & $(0.008)$ \\
& $-2.157^{*}$ & $1.543^{+}$ & -0.041 & 0.019 & $-0.154^{\dagger}$ & $0.905^{*}$ \\
Observations & $(0.618)$ & $(0.935)$ & $(0.134)$ & $(0.118)$ & $(0.091)$ & $(0.141)$ \\
Adj. $R^{2}$ & 942 & 942 & 471 & 942 & 942 & 471 \\
\hline
\end{tabular}

Notes: The Count of Grants parameter estimates are obtained from a negative binomial regression model. The remaining estimates are obtained from probability weighted ordinary least squares regression models. Models include fixed effects for year $=2009$ and for the fifty US states.

$* p<0.05 ;+p<0.10$.

rates $\left(\chi^{2}=13.36 ; p=0.00\right)$ of the individuals on foundation boards are significantly larger for the public-company foundations.

\section{Discussion and Conclusion}

There have been numerous calls for more research into the roles that corporations have played and should play in the provision of social goods and services (Margolis and Walsh 2003). We heed these calls in this article by spotlighting the resources that flow through corporate versus independent foundations to the nonprofits that work in the social sector.

Given their similar stated programmatic and fiduciary objectives, a plausible null hypothesis is that corporate foundations are no different than their independent counterparts (Galaskiewicz and Sinclair-Colman 2006). Like independent foundations, corporate foundations may be run according to the abilities and social interests of the managers charged with running them. Put differently, as separate legal institutions, corporate foundations may be buffered from the financial interests of their sponsor companies. In fact, this is what we would conclude in the context of the sector distribution of grants made by the two types of foundations. Notwithstanding a plausible competitive logic that might lead corporate foundations to favor supporting elite-oriented nonprofits, we find no systematic differences across these two grantee distributions. 
Given the prospect of systematic differences between corporate and independent foundations, it is important to know whether they make us more or less optimistic about the prospect of greater corporate involvement in the foundation sector. Optimistic views suggest that there is real promise in the prospect of forprofit companies becoming more engaged in the social sector. The basic tenets of this argument are that business thinking, and the associated incentives that come from effective company participation in social affairs, provide the resources necessary to scale the provision of critical social goods and services. In this respect, our findings suggest that sponsoring companies do provide organizational platforms that allow corporate foundations to raise funds more effectively and to administer grants with less paid overhead. By leveraging shared resources, foundation-sponsoring companies do increase the volume of resources that flow into the social sector.

Pessimistic views emphasize that corporate foundations are also imprinted (Stinchcombe 1965) by the profit-seeking orientation of their sponsors. This imprinting introduces additional motives for grantmaking that lead corporate foundations to give smaller grants and to have more ephemeral relationships with their grantees. Greater turnover among foundation officers also suggests that their governance is less committed and therefore less consistent over time. Taken together, these findings suggest that managerial preferences and company stakeholder expectations might ultimately limit the extent to which corporate foundations can translate their superior ability to mobilize resources into better supported and thus more scalable social impacts. The fact that these stakeholder effects tend to be more dramatic among the larger and better resourced publicly traded sponsor companies suggests that these inhibitions to focusing attention and resources-both cross-sectionally and dynamically - are more problematic in precisely those places where corporations are thought to have their greatest potential beneficial impact on the provision of social goods and services.

In closing, we note that the nonprofit sector has been characterized in recent decades by its "sweeping moves toward importing business models and practices, which may transform charitable groups into more instrumental, purposive organizations" (Hwang and Powell 2009:271). Company sponsorship of philanthropic foundations may represent the cleanest example of this confluence of business and charity. If corporate foundations move to the forefront of the recent trend toward more rationalized forms of philanthropy, then our findings raise a cautionary flag about unintended consequences. The more obvious implications of more corporate sponsorship-i.e., greater fundraising effectiveness and organizational efficiencyseem unambiguously positive for organizations in the nonprofit sector. However, the more subtle effects-i.e., movement away from strategically and consistently supporting smaller sets of grantees-alter the traditional expectations that nonprofits have come to have in respect to this third pillar of philanthropic support. Perhaps more importantly, if independent foundations aspire to resemble their corporate counterparts due to the pressures of rationalization, then these subtle unintended consequences may become even more salient.

These possibilities clearly warrant further investigation, and our paper suggests several starting points for a potential research agenda. If the observed differences between corporate foundations and their independent counterparts are due to the 
mechanisms that we propose (i.e., resource-sharing and the desire to appeal to a wider range of stakeholders), then we might expect to find further differences within a larger sample of corporate foundations. Larger companies or those with greater levels of slack may be better positioned to raise funds or administer their foundations more effectively due to the prospect of greater resource-sharing. On the other hand, companies with more diverse employees or those that operate in multiple sectors or geographies might be even more likely to give smaller grants and distribute them more broadly if our proposed stakeholder mechanism is indeed driving the results that we obtain.

Progress along these varied lines of inquiry will provide a more detailed response to Margolis and Walsh's (2003) call by moving past the opening questions of whether and how corporate involvement has implications for the workings of the social sector, to addressing what kinds of corporations and contributions tend to deliver these different implications. This type of research agenda will also help push verbal debates about the relative merits of increased corporate participation in the social sector to more nuanced presentations of the specific benefits and costs associated with different kinds of involvement by different kinds of companies. These are the kinds of research projects that will be necessary to uncover the true potential of the business sector to address society's biggest challenges.

\section{Notes}

1 IRS Form 990s are informational returns that report the finances, grantmaking, and management of the foundation. Foundations that do not file annual reports risk losing their nonprofit status. More information on these reports can be found at http://www . guidestar.org/rxg/help/faqs/form-990/index. aspx.

2 Preliminary data searches suggested that these targets would ensure the required information for at least ten grantees from each foundation in each year, or from at least ten percent of the larger foundations' grantees.

3 Three types of grant recipients are not required to report and therefore do not show up in nonprofit databases: individuals (who receive scholarships or financial assistance), religious organizations, and (particularly public) schools. We used the name of the recipient and other information reported by the foundation to identify these three types.

4 When we could only determine the identity of a parent organization or some other affiliate, we used the parent or affiliate EIN for philanthropic sector classification and coded the location as missing. Location information was also supplemented with data reported on the informational forms.

5 See www.nccsdataweb. urban.org.

6 The IRS requires the reporting of all individuals who sit on the foundation's board, plus the top foundation manager (i.e., president or director), and the person in charge of foundation finances. In cases where the foundation mentions additional employees, we include only officers, directors, and trustees.

7 See www . foundationcenter. org.

8 To assess the generalizability of the results obtained from our random matched sample of independent foundations and corporate foundations, we re-estimated models 1 and 2 
on the complete roster of active U.S. foundations in 2005 and 2009 and obtained a similar pattern of results (see models A1 and A2 in the appendix).

9 The continuity measure may be driven in part by some foundations giving very few grants to the same smaller set of organizations over time. In this respect, higher grantee continuity among independent foundations might be due to them making fewer grants overall. However, in an unreported model, we found no difference in the estimated corporate foundation effect on grantee continuity after adding a control for the total number of grants made in 2005.

10 In unreported variants of models 3-8, we added an additional control for the administration ratio. The finding (from model 3 ) that the two types of foundations spend different amounts on overhead might imply underlying differences in how grantmaking decisions are made, which might confound the results that we report. However, we find the results are virtually unchanged from those reported in Table 4.

\section{References}

Brown, William O., Eric Helland, and Janet Kiholm Smith. 2006. “Corporate Philanthropic Practices." Journal of Corporate Finance 12(5):855-77. http://dx.doi .org/10.1016/j . jcorpfin.2006.02.001.

Burt, Ronald S. 1983. "Corporate Philanthropy as a Cooptive Relation." Social Forces 62(2):41949. http://dx.doi.org/10.1093/sf/62.2.419.

Carnegie, Andrew. 1889. “Wealth." The North American Review 148(391):653-64.

Dowie, Mark. 2001. American Foundations: An Investigative History. Cambridge, MA: MIT Press.

Fombrun, Charles and Mark Shanley. 1990. “What's in a Name? Reputation Building and Corporate Strategy." Academy of Management Journal 33(2):233-258. http: //dx. doi .org/ $10.2307 / 256324$

Galaskiewicz, Joseph, Wolfgang Bielefeld, and Myron Dowell. 2006. "Networks and Organizational Growth: A Study of Community Based Nonprofits." Administrative Science Quarterly 51(3):337-80.

Galaskiewicz, Joseph and Michelle Sinclair Colman. 2006. "Collaboration between Corporations and Nonprofit Organizations." Pp. 168-90 in The Nonprofit Sector: A Research Handbook, edited by Walter W. Powell and Richard Steinberg. New Haven, CT: Yale University Press.

Greening, Daniel W. and Daniel B. Turban 2000. “Corporate Social Performance as a Competitive Advantage in Attracting a Quality Workforce." Business and Society 39(3):254-280. http://dx.doi.org/10.1177/000765030003900302.

Guthrie, Doug. 2010. "Corporate Philanthropy in the United States: What Causes do Corporations Back?" Pp. 183-204 in Politics and Partnerships: The Role of Voluntary Associations in America's Political Past and Present, edited by Elizabeth S. Clemens and Douglas Guthrie. Chicago: University of Chicago Press.

Hwang, Hokyu and Walter W. Powell. 2009. "The Rationalization of Charity: The Influences of Professionalism in the Nonprofit Sector." Administrative Science Quarterly 54(2):268-98. http://dx.doi.org/10.2189/asqu. 2009.54.2.268.

Margolis, Joshua D. and James P. Walsh. 2003. “Misery Loves Companies: Rethinking Social Initiatives by Business." Administrative Science Quarterly 48(2):268-305. http: //dx.doi.org/10.2307/3556659. 
Marquis, Christopher, Gerald F. Davis, and Mary Ann Glynn. 2013. "Golfing Alone? Corporations, Elites, and Nonprofit Growth in 100 American Communities." Organization Science 24(1):39-57. http://dx.doi.org/10.1287/orsc.1110.0717.

Nelson, Ralph Lowell. 1970. Company-Sponsored Foundations. Economic Factors in the Growth of Corporation Giving. New York: Russell Sage.

Pfeffer, Jeffrey and Gerald R. Salancik. 1978. The External Control of Organizations: A Resource Dependence Approach. New York: Harper and Row Publishers.

Porter, Michael E. and Mark R. Kramer. 2006. "Strategy and Society." Harvard Business Review 84(12):78-92.

Prewitt, Kenneth. 2006. "Foundations." Pp. 355-77 in The Nonprofit Sector: A Research Handbook, edited by Walter W. Powell and Richard Steinberg . New Haven, CT: Yale University Press.

Stinchcombe, Arthur L. 1965. "Social Structure and Organizations." Pp. 142-55 in Handbook of Organizations, edited by J. G. March. Chicago: Rand McNally.

Walker, Edward T. 2013. “Signaling Responsibility, Deflecting Controversy: Strategic and Institutional Influences on the Charitable Giving of Corporate Foundations in the Health Sector." Research in Political Sociology 21:201-233. http://dx . doi .org/10.1108/ s0895-9935(2013)0000021012.

Acknowledgements: The authors thank Joe Galaskiewicz, Giacomo Negro, faculty at Georgia State University, and participants at the 2012 EGOS Colloquium, the 2013 Society for the Study of Social Problems Annual Meeting, the 2013 American Sociological Association Annual Meeting, the 2014 Alliance for Research on Corporate Sustainability Research Conference, and the 2014 Academy of Management Annual Meeting for their insightful feedback and suggestions.

Justin Koushyar: Goizueta Business School, Emory University. E-mail: justin.koushyar@emory.edu.

Wesley Longhofer: Goizueta Business School, Emory University. E-mail: wesley.longhofer@emory.edu.

Peter W. Roberts: Goizueta Business School, Emory University. E-mail: peter.roberts@emory.edu. 